\title{
Primary extranodal NK/T cell lymphoma: A rare cutaneous malignancy
}

\author{
Nadia Shirazi', Rashmi Jindal ${ }^{2}$, Sohaib Ahmad ${ }^{3}$, Neena Chauhan ${ }^{4}$ \\ Associate Professor, Departments of ${ }^{1}$ Pathology and ${ }^{2}$ Dermatology, Professor, ${ }^{3}$ Departments of General Medicine \\ and ${ }^{4}$ Pathology, Himalayan Institute of Medical Sciences, Swami Rama Himalayan University, Jolly Grant, Dehradun, \\ Uttarakhand, India
}

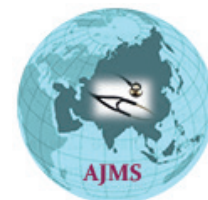

A B S T R A C T

Extranodal Natural Killer cell/T cell lymphomas are subcategorized into ENK/T-nasal and ENK/T-nasal type. These lymphomas presenting as initial involvement of skin are unusual and are known as Primary cutaneous NK/T - nasal type lymphomas. We present a rare case of a middle aged female presenting with rapidly developing skin nodules and ulcers. This case highlights the fact that adequate work up should be done in all such cases to avoid erroneous diagnosis and subsequent inadequate treatment of primary cutaneous lymphoma patients.

Key words: Natural Killer/T cell, Cutaneous, Primary, Immunohistochemistry

\section{Access this article online}

Website:

http://nepjol.info/index.php/AJMS DOI: 10.3126/ajms.v8i1.15943

E-ISSN: 2091-0576

P-ISSN: 2467-9100

\section{INTRODUCTION}

Extranodal NK/T cell lymphoma-Nasal (ENK/T-N) usually involve the upper aerodigestive tract whereas skin, soft tissue, gastro intestinal tract are sites of predilection for Extranodal NK/T cell lymphoma-Nasal Type (ENK/TNT) ${ }^{1}$ Nasal type lymphoma with initial presentation in the skin is known as Primary Cutaneous ENK/T-NT lymphoma (PC-ENK/T-NT). These are rare types of Non Hodgkins Lymphoma characterized by an aggressive clinical course. They account for $<2 \%$ lymphoma in Europe and North America however a slightly increased frequency is noted in Asia and Central and South America (5-10\% of all Non Hodgkins Lymphoma). ${ }^{2}$ These tumors show a short survival time and poor response to therapy. ${ }^{3}$ The 5 year survival ranges from $37.9 \%$ to $45.3 \%$ despite intensive chemotherapy followed by radiotherapy. ${ }^{4} \mathrm{We}$ present this clinically unsuspecting case of $\mathrm{NK} / \mathrm{T}$ cell lymphoma because of it's rarity, aggressive clinical features and thorough diagnostic work up.

\section{CASE}

A 48 year old North Indian female presented to the Dermatology clinic with multiple skin patches and nodules since 2 months. There was no history of fever, night sweats or weight loss. On examination the nodules were mostly present on the extremities, trunk and face. These nodules were erythematous and violaceous (Figure 1). There was no lymphadenopathy, organomegaly or sinonasal involvement. Complete hemogram showed mild anemia $(9.8 \mathrm{~g} / \mathrm{dl})$ however leukocyte and platelet counts were within normal limits. ELISA for HIV, HBsAg and VDRL were non-reactive. A clinical diagnosis of pyoderma gangrenosum was made. Skin biopsy (4 $\mathrm{mm}$ deep) was taken from a nodular lesion in the right forearm and sent for histopathological examination. Biopsy was processed routinely and slide prepared was stained with Hematoxylin and Eosin as well as with Giemsa. Microscopic examination revealed partly atrophic epidermis. Dermis showed sheets of atypical medium to large lymphoid cells with a predominantly angiocentric pattern. Cells had round to convoluted nuclei with coarse chromatin.Mitotic figures were sparse however multiple areas of necrosis admixed with nuclear dust were seen (Photomicrograph 1). A differential diagnosis of lymphoma versus metastatic carcinoma was rendered and Immunohistochemistry (IHC) was performed. IHC showed cytoplasmic CD3 and CD56 positivity and negativity for CK,CD30 and CD20. (Photomicrographs 2,3). Bone marrow examination was 


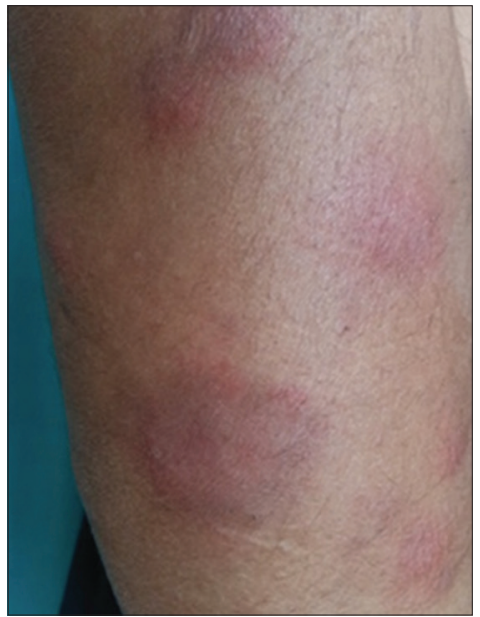

Figure 1: Erythematous nodules on arm

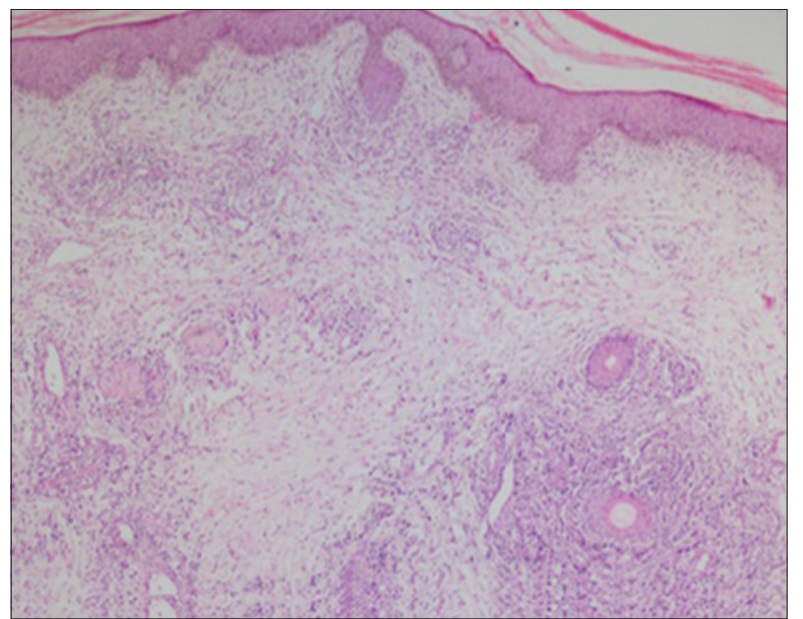

Photomicrograph 1: H\&E: 100X: Dermal infiltrate of atypical lymphoid cells with an angiocentric pattern

unremarkable. On the basis of clinical, histopathological and Immunohistochemical features a diagnosis of primary cutaneous extranodal NK/T cell lymphoma was made. She was given 2 cycles of systemic chemotherapy with the CHOP (cyclophosphamide, doxorubicin, vincristine, and prednisolone) regime. The patient came back with relapse within 7 months of initial therapy.

\section{DISCUSSION}

Primary Cutaneous ENK/T-NT lymphoma (PC-ENK/T-NT) is a rare cutaneous malignancy with an aggressive clinical course. Cutaneous lesions show morphologic heterogeneity with varied manifestations such as multiple erythematous nodules, erythematous to violaceous well-demarcated plaques and nodules, ulcero-necrotic lesions with bulla formation, poorly circumscribed erythematous patches and multiple large ulcers. Our case also presented with multiple erythematous

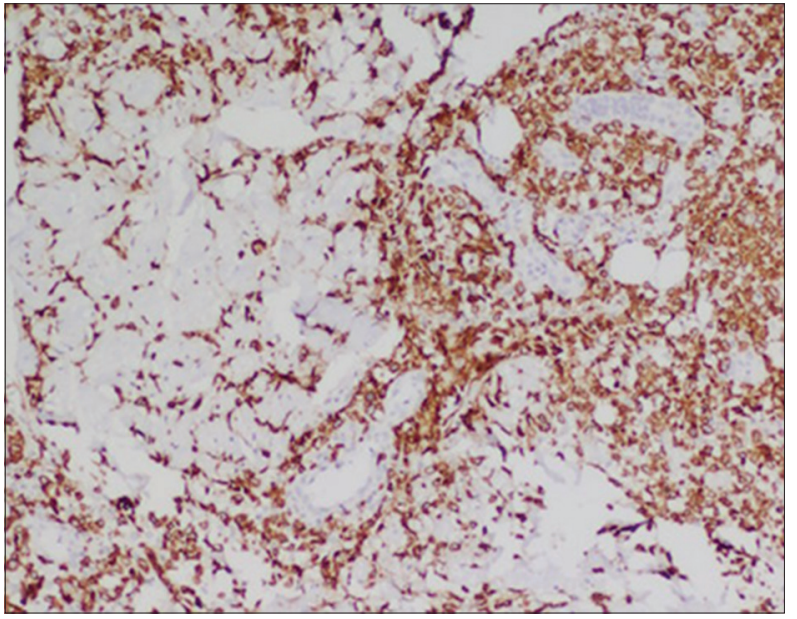

Photomicrograph 2: Immunohistochemistry (CD 56): 400X: Strong cytoplasmic positivity seen in tumor cells

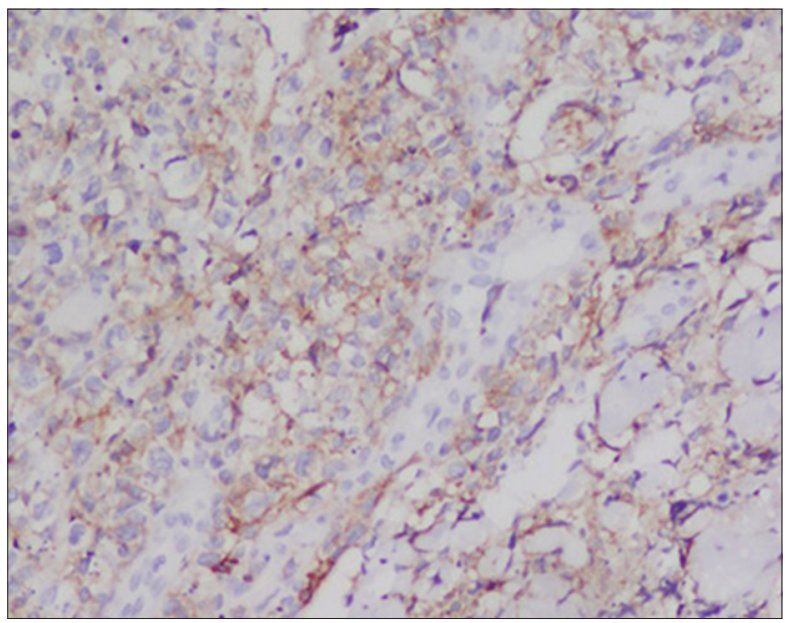

Photomicrograph 3: Immunohistochemistry (CD 3): 400X: Cytoplasmic positivity seen

nodules with few exhibiting ulceration. Histopathologically, these tumors show atypical lymphoid cells in dermis with an angiocentric pattern of infiltration. Necrosis is usually present. Sometimes plasma cells and neutrophils may be seen admixed with these neoplastic lymphoid cell and lead to a false negative diagnosis. Thus careful recognition of atypical lymphoid cells, their angiocentric disposition and presence of conspicuous necrosis should raise the suspicion of $\mathrm{NK} / \mathrm{T}$-cell lymphoma.The lymphoid cells express certain cytotoxic molecules which leads to apoptosis of tumor cells as well as some inflammatory cells like neutrophils. The immunohistochemical profile of tumor cells is mandatory for a definite diagnosis. The common immunophenotype is $\mathrm{CD} 2^{+}, \mathrm{CD}_{5} 6^{+}$, surface $\mathrm{CD}^{-}$, cytoplasmic $\mathrm{CD} 3 \epsilon^{+}$, cytotoxic granules associated proteins and EBV-encoded RNA (EBER)-EBV ${ }^{+}{ }^{5}$ In the present case, IHC for EBV was not performed however the neoplastic cells were positive for CD56, CD2 and cytoplasmic CD3. Loss of $6 \mathrm{q}$ is a frequently reported 
genomic alteration in ENK/T lymphomas however the significance is not clear. ${ }^{6} \mathrm{Li}$ et al detected abnormal expression of the $\mathrm{p} 53$ protein and mutation of the TP53 gene in a wide range of cases.These genes are involved in the cell cycle, and their loss is described in tumor formation in mosttissues, particularly in cases of leukemia and lymphoma. ${ }^{7}$

Some studies have reported that localized cutaneous manifestations are related to a less fulminant course and a better survival outcome. ${ }^{89}$ The extent of initial skin involvement does not reliably predict outcome, however if regional lymph nodes are involved the patient may deteriorate more rapidly with a median survival of less than 15 months. ${ }^{10}$

\section{CONCLUSION}

Extranodal cutaneous NK/T cell lymphoma is an aggressive neoplasm. The presence of systemic or nodal disease at presentation is the most important clinical variable and portends a poor prognosis. All cases of rapidly developing erythematous nodules should be further evaluated for an underlying malignant disease. Histopathology with Immunohistochemistry remains the gold standard for making a definite diagnosis.

\section{REFERENCES}

1. Swerdlow SH, Campo E, Harris NL, Jaffe ES, Pileri SA, Stein H, et al. World Health Organization Classification of Tumors of
Haematopoietic and Lymphoid Tissues. Lyon, France: IARC Press. 2008. 285-288.

2. Anderson JR, Armitage JO and Weisenburger DD. Epidemiology of the non-Hodgkin's lymphomas: distributions of the major subtypes differ by geographic locations. Non-Hodgkin's Lymphoma Classification Project. Ann Oncol 1998; 9(7):717-720.

3. Au WY, Ma SY, Chim CS, Choy C, Loong F, Lie AK, et al. Clinicopathologic features and treatment outcome of mature T-cell and natural killer-cell lymphomas diagnosed according to the World Health Organization classification scheme: a single center experience of 10 years. Ann Oncol 2005; 16(2):206-214.

4. Lee J, Park YH, Kim WS, Park SH, Park KW, Kang JH, et al. Extranodal nasal type NK/T-cell lymphoma: elucidating clinical prognostic factors for risk-based stratification of therapy. Eur $\mathrm{J}$ Cancer 2005; 41(10):1402-1408.

5. Schwartz EJ, Molina-Kirsch H, Zhao S, Marinelli RJ, Warnke RA and Natkunam Y. Immunohistochemical characterization of nasaltype extranodal NK/T-cell lymphoma using a tissue microarray: an analysis of 84 cases. Am J Clin Pathol 2008; 130(3):343-351.

6. Ko YH, Choi KE, Han JH, Kim JM and Ree HJ. Comparative genomic hybridization study of nasal-type NK/T-cell lymphoma. Cytometry 2001; 46(2):85-91.

7. Li T, Hongyo T, Syaifudin M, Nomura T, Dong Z, Shingu N, et al. Mutations of the p53 gene in nasal NK/T-cell lymphoma. Lab Invest 2000; 80(4):493-499.

8. Kim K, Chie EK, Kim CW, Kim IH and Park Cl. Treatment outcome of angiocentric T-cell and NK/T-cell lymphoma, nasal type: radiotherapy versus chemoradiotherapy. Jpn J Clin Oncol 2005; 35(1):1-5.

9. Choi YL, Park JH, Namkung JH, Lee JH, Yang JM, Lee ES, et al. Extranodal NK/T-cell lymphoma with cutaneous involvement: 'nasal' vs. 'nasal-type' subgroups-a retrospective study of 18 patients. Br J Dermatol 2009; 160(2):333-337.

10. Suzuki R, Suzumiya J, Yamaguchi M, Nakamura S, Kameoka J, Kojima $\mathrm{H}$, et al. Prognostic factors for mature natural killer (NK) cell neoplasms: aggressive NK cell leukemia and extranodal NK cell lymphoma, nasal type. Ann Oncol 2010; 21(5):1032-1040. 